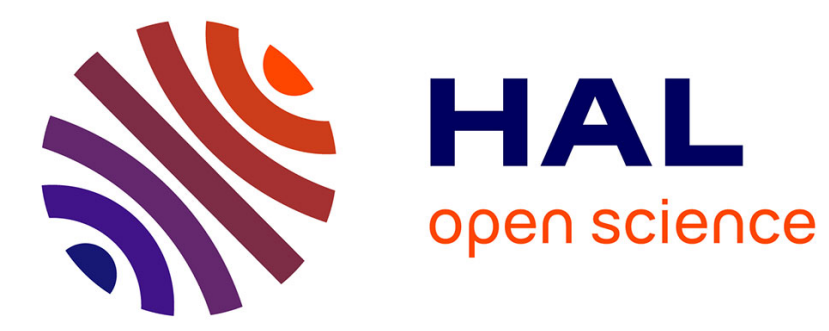

\title{
Sesamoid bones also show functional adaptation in their microanatomy-The example of the patella in Perissodactyla
}

\author{
Alexandra Houssaye, Adrien de Perthuis, Guillaume Houée
}

\section{To cite this version:}

Alexandra Houssaye, Adrien de Perthuis, Guillaume Houée. Sesamoid bones also show functional adaptation in their microanatomy-The example of the patella in Perissodactyla. Journal of Anatomy, 2021, 10.1111/joa.13530 . hal-03357183

\section{HAL Id: hal-03357183 \\ https://hal.science/hal-03357183}

Submitted on 28 Sep 2021

HAL is a multi-disciplinary open access archive for the deposit and dissemination of scientific research documents, whether they are published or not. The documents may come from teaching and research institutions in France or abroad, or from public or private research centers.
L'archive ouverte pluridisciplinaire HAL, est destinée au dépôt et à la diffusion de documents scientifiques de niveau recherche, publiés ou non, émanant des établissements d'enseignement et de recherche français ou étrangers, des laboratoires publics ou privés. 
1 Sesamoid bones also show functional adaptation in their microanatomy -

2 the example of the patella in Perissodactyla

3

4

5

6

${ }^{1}$ UMR 7179 CNRS/Muséum National d'Histoire Naturelle, Département Adaptations du

7 vivant, 57 rue Cuvier CP-55, 75005 Paris, France.

8

9 RH: Patella microanatomical adaptation in Perissodactyla

10

11

12

13

14

15

16

17

18

19

20

21

22

23 *Corresponding author 


\section{Abstract}

The patella is the largest sesamoid bone of the skeleton. It is strongly involved in the knee, improving output force and velocity of the knee extensors, and thus plays a major role in locomotion and limb stability. However, the relationships between its structure and functional constraints, that would enable a better understanding of limb bone functional adaptations, are poorly known. This contribution proposes a comparative analysis, both qualitative and quantitative, of the microanatomy of the whole patella in perissodactyls, which show a wide range of morphologies, masses and locomotor abilities, in order to investigate how the microanatomy of the patella adapts to evolutionary constraints. The inner structure of the patella consists of a spongiosa surrounded by a compact cortex. Contrary to our expectations, there is no increase in compactness with bone size, and thus body size and weight, but only an increase in the tightness of the spongiosa. No particular thickening of the cortex associated with muscle insertions is noticed but a strong thickening is observed anteriorly at about midlength, where the strong intermediate patellar ligament inserts. The trabeculae are mainly oriented perpendicularly to the posterior articular surface, which highlights that the main stress is antero-posteriorly directed, maintaining the patella against the femoral trochlea. Conversely, anteriorly, trabeculae are rather circumferentially oriented, following the insertion of the patellar ligament and, possibly also, of the quadriceps tendon. A strong variation is observed among perissodactyl families but also intraspecifically, which is in accordance with previous studies suggesting a higher variability in sesamoid bones. Clear trends are nevertheless observed between the three families. Equids have a much thinner cortex than ceratomorphs. Rhinos and equids, both characterized by a development of the medial border, show an increase in trabecular density laterally suggesting stronger stresses laterally. The inner structure in tapirs is more homogeneous despite the absence of medial development of the medial border with no "compensation" of the inner structure, which suggests different stresses on their knees associated with a different morphology of their patellofemoral joint.

Key words: Bone microanatomy; Functional adaptation; Patella; Perissodactyla 


\section{Introduction}

The skeleton is influenced by diverse constraints including phylogenetic heritage, functional, developmental, and structural constraints (Seilacher, 1970; Gould, 2002; Barr, 2018; Jones et al., 2018). Bones show a strong from-function relationship in their outer shape but also in their inner structure (Carter et al., 1991; Currey, 2003; Kley et al. 2007; Yang et al., 2017; Dunn, 2018). More plastic than bone morphology, bone micronanatomy bears a strong functional signal and is generally only slightly influenced by phylogeny (Ferry et al., 2011; Dumont et al., 2013; Kivell, 2016; Vlachopoulos et al., 2017; Montoya-Sanhueza and Chinsamy, 2018). Beyond the evolutionarily inherited traits, bone microanatomy also adapts to functional constraints during the lifetime of organisms (Warden et al., 2007; Sievänen, 2010; Reina et al., 2017). At both time scales, bone inner structure is influenced by size and weight (Houssaye \& Tafforeau, 2012; Dumont et al., 2013; Houssaye et al., 2016a; Iwaniec \& Turner, 2016; Saers et al., 2020).

Many studies have been conducted in order to link bone microanatomical features to animal functional requirements in an evolutionary perspective. Various bones have been investigated, such as skull bones (Zioupos et al., 1997; Amson et al., 2018), vertebrae (Dumont et al., 2013; Houssaye et al., 2014), ribs (Buffrénil et al., 2010 ; Canoville et al., 2016), pelvic bones (Volpato et al., 2008 ; Díaz Berenguer et al., 2018), limb long bones (Quemeneur et al., 2013; Montañez-Rivera et al., 2018), and autopod bones (Thomason, 1985 ; Dunmore et al., 2019). However, very few data exist about the inner structure of sesamoid bones.

In the context of understanding limb bone functional adaptations, one sesamoid bone of particular interest is the patella. This bone, which is the largest of the sesamoid bones, has long been considered to ossify into the main extensor tendon of the quadriceps femoris. However, it may instead form initially alongside the femur from which it is subsequently detached by the formation of a synovial joint. The patella then becomes embedded in the quadriceps tendon (Eyal et al. 2015; 2019) separating it into two parts: the quadriceps tendon and the patellar ligament(s) (also referred to as patellar tendon; Samuels et al., 2017; Dan et al. 2018); and also articulates with the femur. It is thus part of the patellofemoral joint, one of two articulations (with the tibiofemoral joint) composing the knee. The patella ensures the continuity between the quadriceps tendon and the patellar ligament. It is assumed to protect the tendons and articular cartilage from excessive compression and to increase the lever arm of the quadriceps extensor mechanism, thereby improving its efficiency (Aglietti \& 
Menchetti, 1995; Mottershead, 1988; Sarin \& Carter, 2000). This enables the improvement of both output force and output velocity of the knee extensors (Allen et al., 2017). However, the link between this bone structure and the functional constraints experienced at the knee joint remain only partially known. Some studies have investigated the possible mechanical advantage of this bone (Ellis et al., 1980; Alexander \& Dimery, 1985; Lovejoy, 2007; Allen et al., 2017; Pina et al., 2020). The inner structure has been investigated in humans (Raux et al., 1975; Toumi et al., 2006). But investigations of the form-function relationships through a comparative analysis including various animals are scarce (Valois, 1917; Raymond \& Prothero, 2010; Pina et al., 2020).

Within mammals, the patella displays a wide range of sizes but is described as rather conservative in shape (Samuels et al., 2017). The structure is hemispherical, with a convex outer surface covered by fibrocartilage and tendon fibers (Clark \& Stechschulte, 1998; Benjamin et al. 2006), and a concave inner surface articulating with the femoral groove. As for the inner structure, it is essentially spongious, surrounded by a compact cortex (Raux et al., 1975). Data on the variability in the structure of this bone and its possible drivers are thus scarce.

The present contribution proposes to analyze the inner structure of this bone in various mammals in order to investigate how its microanatomy adapts to evolutionary constraints. One group of interest for this question is the perissodactyls. The odd-toed ungulates nowadays include the equids, tapirs and rhinos, and thus animals with a wide range of morphologies, masses (from a hundred kilos in lightly built horses to over two tonnes in massive rhinos), habitats (from mountainous forests to savannahs), and locomotor abilities (with distinct running performances between the three families). High body weight is considered to be associated with increased bone compactness (i.e. volume of osseous tissue over the total bone volume; Currey \& Alexander, 1985; Houssaye et al., 2016b;c). The patella transmits to the femur, through the patellofemoral joint, forces of the quadriceps muscle that can reach up to 20-25 times body weight (Aglietti \& Menchetti, 1995; Samuels et al., 2007) so that we can first assume patellae of heavy animals to be more compact that those of lighter ones. During this process, the patella is also under high tensile stress, being pulled both proximally and distally. Since trabeculae tend to orient themselves in the direction of principal stress (Turner, 1998; Pontzer et al., 2006; Barak et al., 2011), we could also expect the main trabecular orientation to be proximo-distal, at least away from the compression of the patella against the femur. Moreover, the distal part of the femur varies between the perissodactyl families and suggests various functional requirements; equids and rhinos are notably characterized by a 
strongly asymmetrical femoral trochlea supposed to increase the locking mechanism of the knee (Hermanson \& MacFadden, 1996; Schuurman et al. 2003; Janis et al., 2012). Because of the patellofemoral joint, variations of the functional constraints on the patellae are also expected and should be reflected in the organization of the trabecular network since bone inner structure adapts to the functional constraints it undergoes (Wolff, 1986; Huiskes et al., 2000). We thus additionally assume the trabecular organization to vary between these taxa according to morphological changes of the patellofemoral joint. Moreover, while the link between muscle activity and attachment site morphology is dubious (Zumwalt, 2005; Rabey et al. 2015), some studies have highlighted that cortical bone appears to be thicker at muscle attachment sites, so that, finally, we expect differences in muscle topography to be reflected in variations in cortical bone thickness (Niinimaki et al 2013; Djukic et al., 2015; Harbers et al. 2020). The link between muscles and bone structure is complex, as it relies on various parameters in addition to muscle activity and attachment site, including the type of entheses and the angle of muscle attachment to the bone surface (Djukic et al., 2015). In this study we plan to document variations in cortical bone thickness along the bones to highlight possible relationships with muscle/tendon attachment sites.

To examine the microanatomical adaptive features in this sesamoid bone, we thus investigate both cortical and trabecular bone. This analysis takes the whole bones into consideration, in three dimensions, both qualitatively and quantitatively, and in a comparative perspective. This allows us to describe in detail the inner structure of this sesamoid bone in perissodactyls, and its variation within perissodactyls, to characterize the relationships between the inner structure and the functional constraints undergone by this bone, and notably its association with mass, support, and locomotion in the evolutionary history of perissodactyls.

\section{Material and Methods}

\section{Material}

The sample consists of 29 patellae belonging to the five modern rhino species (15), three of the four modern species of tapirs (7) and four of the seven modern species of equids (7), which enables us to encompass most of the diversity of modern Perissodactyla (Table 1; Fig. 1). The bones come from the collections of the Museum National d'Histoire Naturelle (MNHN, Paris, France), of the Natural History Museum (NHM, London, UK), and of the Naturhistorisches Museum (NHM, Basel, Switzerland). The number of bones by species 
relies on accessibility and on the state of preservation since patellae are often not preserved in the collections (maybe thrown away with the tendon) or drilled during mounting.

\section{Methods}

\section{Data acquisition}

Bones were scanned using high-resolution computed tomography at the: 1) MRI platform, hosted at the ISEM, University of Montpellier (UMR 5554; EasyTom 40-150, RX Solutions); 2) micro-CT laboratory of the Natural History Museum, London, UK (Nikon HMX 225 ST system), and 3) AST-RX platform at the Museum National d'Histoire Naturelle, Paris (UMS 2700; GE phoenix|X-ray v|tome|xs 240), with reconstructions performed using X-Act (RX Solutions), the CT-agent software (Nikon Metrology, Leuven, Belgium), and DATOX/RES software (phoenix datos|x). Voxel size naturally varies depending on specimen size (Table 1). Bone tissues were entirely segmented to analyze the microstructure of the complete bones.

The compact cortex was then separated from the spongiosa by manual segmentation (allowing the distinction between bone and soft tissue even when the grey levels are very close) coupled with the 'smooth labels' function (avoiding artificial increments between successive reconstructed slices and thus offering a more natural contour) in Avizo 9.4 (VSG, Burlington, MA, USA) in order to be relatively objective and reproducible so that they could be analyzed separately. Then, in order to quantify the thickness of the layer of compact cortex, we isolated the outer surface of the bone and an inner surface (corresponding to the inner limit of the compact cortex or outer limit of the trabecular area) for each bone, using 'fill', and adding 'remove islands' to remove the intracortical cavities. The cortical thickness was calculated using 'distance' between these two surfaces. This also enabled us to obtain bone cartographies in order to visualize the relative variation in cortical thickness along each bone. The different volumes obtained (whole bone tissue, compact bone tissue, trabecular bone tissue, spongiosa, whole bone) were then converted into image stacks in order to measure several parameters (see below).

In addition, for qualitative comparisons three virtual sections were obtained for each patella, following Barone (2010) for orientation (the apex being the distalmost point and the relief vertical in posterior view, the relief being rather rectilinear [with the most posterior parts aligned] and the most medial part of the bone becoming not observable in lateral view) and 
terminology (Fig. 2): 1) one coronal section (CS; in the medio-lateral plane) at the level of the posteriormost extremity of the lateral angle, and 2) two sagittal sections (in the anteroposterior) plane, at the level of the deepest part of the medial articular facet (SS1) and of the apex (distal extremity on the posterior surface), along the relief (SS2; Fig. 2). Since no reference sections for the patella already exist in the literature, these sectional planes were chosen because they enable us to illustrate large portions of the bone to analyze the organization of the trabecular network (e.g. main orientation, density of the trabeculae) and could easily be created with good reproducibility for all specimens. Image segmentation and visualization were performed from the reconstructed image data using Avizo 9.4, and virtual sections with VGSTUDIO MAX, versions 2.2 (Volume Graphics Inc.).

\section{Data analysis}

Various quantitative parameters were used to describe the inner structure (Table S1), based on values directly obtained in Avizo, following Houssaye et al. (2018): 1) Whole bone volume (WBV), based on the segmentation of the osseous tissues and filling of the inner cavities; 2) the bone compactness $(\mathrm{C})$, which was calculated based on WBV and on the bone tissue volume $(\mathrm{BTV}): \mathrm{C}=\mathrm{BTV} * 100 / \mathrm{WBV} ; 3)$ the relative fraction of trabecular bone tissue (\% Trab): \% Trab = trabecular bone tissue volume*100/BTC; 4$)$ the trabecular compactness (TC): $\mathrm{TC}=$ trabecular bone tissue volume*100/ trabecular volume (= volume of the spongiosa, i.e., trabecular bone and intertrabecular spaces). In addition, two parameters were obtained using 'distance', based on MaxT: maximal cortical thickness and MeanT: mean cortical thickness: 5) RMaxT and 6) RMeanT (relative maximal and mean thicknesses), obtained by dividing MaxT and MeanT by a mean radius, calculated from WBV approximating the bone to a sphere.

We selected the following parameters: bone compactness $(\mathrm{C})$, relative fraction of trabecular bone tissue (\% Trab), trabecular compactness (TC), relative maximal (RMaxT) and mean (RMeanT) thicknesses. All these parameters are dimensionless ratios. We kept the whole bone volume (WBV) as a size estimate, in order to test the influence of size on all parameters by performing linear regressions of each parameter to WBV (lm function [stats]). ANOVAs and ANCOVAs (when the influence of size on the parameter was significant) were performed to test for differences between the three families.

Despite the small sample size and intraspecific variation, we tested the phylogenetic signal for each of these parameters in order to provide a rough estimate of the strength (weak, average 
or strong) of the relationship between the parameters and phylogeny. We followed Steiner and Ryder (2011) for the phylogeny, which includes all analyzed species, setting all branch lengths to one and without testing for alternative phylogenetic hypotheses related to the unresolved position of Dicerorhinus (Willersley et al., 2009; Gaudry, 2017), given the gross nature of this test. For that we averaged the values obtained for each species when several specimens from the same species were available. Then we calculated the K-statistic following Blomberg et al. (2003) for each parameter and performed randomization tests. The K-statistic compares the observed phylogenetic signal in a trait with the signal under a Brownian motion model of trait evolution. A K-value > 1 implies more similarity between relatives than expected under Brownian motion; $\mathrm{K}<1$ highlights convergences. In order to analyze quantitatively the distribution of the different specimens in the microanatomical morphospace, but also for the purpose of evaluating how the different microanatomical parameters drive the variation observed in our sample, we conducted normalized PCAs (David \& Jacobs, 2014) on the raw data (Table S1). All statistical analyses were performed using statistical software $\mathrm{R}$ ( $\mathrm{R}$ Core Team 2014 [FactoMineR, ggplot2, ape]).

\section{Results}

\section{Qualitative description}

The bones essentially consist of a spongiosa, which is surrounded by a compact cortex.

\section{Coronal sections}

In all rhino specimens, the spongiosa is dense and tightly packed with some large vascular canals piercing the cortex and not directed according to the main orientations of the trabecular network (Fig. 3A-E). The abundance of these large canals varies depending on specimens, being higher in Rhinoceros sondaicus MNHN-ZM-AC-A7970 and NHMUK ZD 1871.12.29.7 and in Ceratotherium simum MNHN-ZM-MO-2005-297, and lower in Dicerorhinus sumatrensis NHMUK ZE 1948.12.20.1 and NHMUK ZD 1894.9.24.1 and in $R$. sondaicus NHMUK ZD 1921.5.15.1; it thus appears not to be linked with taxon or size. The cortex is thin but it thickens around the borders of the medial and lateral angles and of the apex (Fig. 3A-E). The trabeculae are rather homogeneously organized with no preferential orientation. A large part of the spongiosa near the lateral angle is compacted in specimens of Diceros bicornis (MNHN-ZM-AC-1944-278 and NHM 1876.9.26.6), R. unicornis (NHMUK 
ZD 1884.1.22.1.2 and NHMUK ZD 1972.822), R. sondaicus (NHMUK ZD 1861.3.11.1), and Ds. sumatrensis (NHMUK ZD 1894.9.24.1).

In tapirs, the spongiosa is very homogeneous and the cortex is thin but thickens along the lateral border (Fig. 3F-H). There seems to be a slight change in the orientation of the trabeculae between the upper and lower parts of the bone in the two specimens of Tapirus terrestris (Fig. 3H).

In equids, the cortex is proportionally much thinner (Fig. 3I-L). There is a circumferential orientation of the trabeculae at the bone periphery from the bottom of the medial angle to that of the lateral one. A thin compact layer is observed in periphery medially to the apex in Equus asinus MNHN-ZM-2005-717, Equus caballus MNHN-ZM-AC-A541, and Equus caballus przewalskii MNHN-ZM-AC-1975-124 (Fig. 3I-J); this feature is thus not linked with taxon or size. Moreover, there is a tendency to show a change in the orientation of the trabeculae between the upper and lower parts of the bone, with a more proximo-distal orientation in the lower part; this feature is notably visible in Equus asinus MNHN-ZM-2005-717, Equus caballus przewalskii MNHN-ZM-AC-1975-124, and Equus zebra MNHN-ZM-AC-1948-54 (Fig. 3I,J,L).

\section{Sagittal sections}

SS1. In rhinos, a thick layer of compact cortex surrounds the anterior part of the bone, with a maximal thickness in the lower half of the bone (Fig. 4A-B). The thickness of compact bone on the posterior border varies between taxa, being minimal in Ceratotherium simum MNHNZM-MO-2005-297, Dicerorhinus sumatrensis NHMUK ZE 1948.12.20.1, and Rhinoceros sondaicus MNHN-ZM-AC-A7970, and maximal in Ds. sumatrensis NHMUK ZD 1894.9.24.1 (Fig. 4A-B). Trabeculae are antero-posteriorly oriented on the proximal half of the bone whereas they are more randomly oriented in the distal half; this pattern is not distinguished in Rhinoceros unicornis MNHN ZM-AC-1967-101, NHMUK ZD 1972.822 and NHMUK ZE 1961.5.10.1. There is a circumferential orientation of the trabeculae along the anterior cortex essentially in the distal half of the bone.

In tapirs, the cortex is also thickened on the anterior border (Fig. 4C-D). The trabecular network is rather loose in Tapirus terrestris and T. pinchaque with a clearly dominant anteroposterior (more precisely, at about $90^{\circ}$ to the posterior border) orientation of the trabeculae, except along the anterior border where they are circumferentially oriented, especially in the proximal half of the bone (Fig. 4D). The trabeculae are less antero-posteriorly oriented in $T$. indicus (Fig. 4C). 
In equids, the cortex is rather thin with only a clear thickening along the anterior border around its mid-length (Fig. 4E-F). The orientation of the trabeculae follows that of most tapirs with a wider layer of circumferentially arranged trabeculae distalo-anteriorly.

SS2. In rhinos there is a clear thickening of the cortex along the anterior border, extending, to a much lower extent, along the anterior parts of the proximal and distal borders (Fig. 5A-C). The spongiosa is rather dense and tightly built, i.e., with numerous trabeculae and small intertrabecular spaces. Tightness strongly increases around the core of the posterior border in Ceratotherium simum (Fig. 5A) and two specimens of Rhinoceros sondaicus (MNHN-ZMAC-A7970 and NHMUK ZD 1871.12.29.7), whereas it is much less obvious in the other specimens. In the most proximal part of the bone, the trabeculae are antero-posteriorly oriented but rather randomly oriented elsewhere, except along the anterior border where they show a circumferential organization in most specimens. However, in Dicerorhinus sumatrensis the antero-posterior orientation appears dominant proximo-distally and is not restricted to the most proximal part of the bone (Fig. 5C).

In Tapirus indicus the organization is rather similar as in Ds. sumatrensis, with some thickening of the bone around the core of the posterior border, but with a slightly less tight spongiosa. Tightness is much lower in the two other tapirs and the thickening around the posterior border is discrete (Fig. 5E).

The pattern in equids is very similar to that of the specimens of Ds. sumatrensis (Fig. 5F).

\section{Bone cartographies}

Bone cartographies enabled us to visualize the relative variation in cortical thickness along the entire bone and to make comparisons between the various bones. In all taxa analyzed, cortical thickness is maximal on the anteriormost part of the bone (Fig. 6). The thickened area is rather wide, with a peak that is not clearly distinct and that is rather central and slightly proximally located.

In Ceratotherium, Dicerorhinus, Rhinoceros sondaicus and $R$. unicornis, there is also a more localized thickening in posterior view around the core of the lateral facet, whereas a more laterally localized thickening is observed in Diceros, with both occurring in Rhinoceros unicornis (Fig. 6A-F).

In tapirs there is a slight posterior thickening on the core of the relief in one specimen of Tapirus indicus (MNHN-ZM-AC-1931-528; Fig. 6G) but not on the others. In both specimens of T. terrestris, a thickening is observed at mid-length of the lateral border (Fig. 6J). 
In equids, there is a thickening posteriorly in the proximal half of the relief in Equus hemionus, in one specimen of Equus asinus (MNHN-ZM-AC-1893-634), and in Equus zebra (Fig. 6K,M).

\section{Quantitative analyses}

Five quantitative parameters were analyzed: bone compactness $(\mathrm{C})$, relative fraction of trabecular bone tissue (\% Trab), trabecular compactness (TC), relative maximal (RMaxT) and mean (RMeanT) thicknesses.

A significant, at $\mathrm{p}=0.05$, phylogenetic signal is obtained for \% Trab, RMaxT and RMeanT, with $\mathrm{K}$ values around 1 for thickness indices and clearly higher for \% Trab. Size (estimated based on WBV) also shows a significant phylogenetic signal (Table 2). No parameter shows a significant correlation with size (Table 2). Compactness significantly differs between the three families (Mean values of $65.4 \pm 7.3,56.6 \pm 10.4$, and $56.6 \pm 6.3$ in rhinos, tapirs, and equids, respectively; ANOVA. $\mathrm{p}=0.02$ ) but the range of values is rather wide in the three families, especially for rhinos and tapirs (Fig. 7). Within rhinos, Diceros and R. unicornis show the highest values, except $R$. unicornis NHMUK ZD 1884.1.22.1.2 that groups with the three other species. Dicerorhinus shows the lowest values. Within tapirs, there is a large intraspecific variation. For \% Trab, there is a clear distinction (with almost no overlap) between equids and ceratomorphs (i.e. tapirs and rhinos; Fig. 1) even when size is taken into consideration (Mean values of 55.5 $\pm 5.8,53.3 \pm 6.0$, and $71.1 \pm 4.8$ in rhinos, tapirs, and equids, respectively; ANCOVA; $\mathrm{p}<0.001)$. Equids thus clearly show a much thinner cortex than ceratomorphs (Fig. 7). Within rhinos and tapirs, intraspecific variation is high. TC does not significantly differ between the three families (Mean values of 51.5 $\pm 7.9,41.6 \pm 12.3$, and 48.2 \pm 6.2 in rhinos, tapirs, and equids, respectively; ANOVA; $\mathrm{p}=0.27$ ). Within rhinos, it is higher in Diceros and R. unicornis, except again for $R$. unicornis NHMUK ZD 1884.1.22.1.2 (Fig. 7). Again, intraspecific variation is high. RMaxT and RMeanT are significantly lower in equids even when size is taken into consideration (Mean values of $32.3 \pm 3.5,27.3 \pm 6.5$, and 19.6 \pm 3.3 for RMaxT and 8.0 $\pm 1.8,6.1 \pm 2.0$, and 3.5 \pm 1.2 for RMeanT in rhinos, tapirs, and equids, respectively; ANCOVA; $\mathrm{p}<0.001$ for the two parameters). There is intraspecific variation but a tendency for Diceros to show the highest values within rhinos and Ceratotherium the lowest ones, and $T$. indicus the highest values within tapirs and $T$. pinchaque the lowest ones for RMaxT but not for RMeanT (Fig. 7). 
The first two axes of the PCA, which represent $95.2 \%$ of the variance (66.9 and $28.3 \%$, respectively; Table S2), enable us to distinguish equids from rhinos and tapirs but not rhinos from tapirs (Fig. 8; neither does PC3). The first axis distinguishes equids, on the negative side, from rhinos, on the positive one, whereas tapirs are more widely distributed along PC1. This axis is essentially driven by RMeanT, RMaxT, C and, to a lesser extent, TC (Fig. 8). Rhinos thus show more compact bones with a relatively thicker compact cortex than equids. PC2 distinguishes tapirs, on the negative side, from equids, on the positive one, with a slight overlap, while rhinos have a distribution overlapping with the distribution of tapirs and equids. PC2 is essentially driven by \% Trab, TC and, to a lesser extent, $\mathrm{C}$ (Fig. 8). Equids have a significantly wider spongiosa rather more compact than tapirs. Neither PC1 nor PC2 is correlated with size (Table 2).

\section{Discussion}

\section{Common patterns among Perissodactyla}

In all perissodactyls sampled the inner structure of the patella consists of a spongiosa surrounded by a compact cortex. The maximal cortical thickness is observed anteriorly at about mid-length, at the insertion of the intermediate patellar ligament (Fig. 6, 9A), which is very strong in ungulates (Budras et al. 2003; Barone, 2010; Abumandour et al. 2020). Ligament and muscle insertions on the patella are rather similar between horses and rhinos and thus supposedly across all perissodactyls (Barone, 2010; Etienne et al., 2021). The intermediate patellar ligament is surrounded by the lateral and medial patellar ligaments, which also insert on the anterior side (Fig. 9A), but no clear specific thickening associated with the insertion of these two ligaments is observed in the sampled taxa. The lateral ligament probably inserts where thickness is relatively high around the peak, but no thickening is observed medially. These ligaments link the anterior part of the patella to the tibial tuberosity and thus play a major role in locomotion and limb stability (Barone, 2010). Some specimens show a thickening of the cortex between the relief and the lateral angle in posterior view. This could be linked to the insertion of the lateral patellofemoral ligament, which (with the medial ligament) help to maintain the patella in front of the trochlea, though it inserts on the parapatellar fibrocartilage (Barone, 2010) and is thus less likely to be directly associated with a cortical thickening on the patella. There is no thickening proximally and more generally no thickening that appears associated with the insertions of the quadriceps femoris muscle (Figs 6, 9B). 
As for the spongiosa, there is a clearly dominant antero-posterior orientation of the trabeculae, which is approximately perpendicular to the posterior articular surface. The main trabecular orientation is assumed to reflect the direction of maximal stress (Wolff, 1986; Huiskes et al., 2000). Accordingly, the main stress would be antero-posteriorly directed. This might be associated with maintaining the patella against the femoral trochlea, which would be consistent with previous studies showing the strong shape adaptation between the patellar articular surface (ridge and facets) and the femoral trochlea allowing a more stable patellar alignment (Fujikawa et al. 1983; Wang et al. 2016). This would also be consistent with the main functional role of the patella being to increase the moment arm. This compression results from the tension exerted proximally and distally by the quadriceps tendon and the patellar ligament (Ellis et al., 1980; Aglietti \& Menchetti, 1995) and the primary orientation would reflect the resultant force of this tension. However, considering the diversity in the orientation of the trabeculae in long bones, in both the epiphyses and metaphyses, and in short bones (e.g., Thomason, 1985; Jang \& Kim, 2009; Kivell et al. 2018; Bird et al. 2021; AH. Pers. Obs.), if an anteroposterior orientation of the trabeculae in the core of the bone is coherent, it nevertheless appears surprising not to see a progressive shift from the proximal and distal surfaces to the core of the bone, from one direction of tension (and thus a rather proximo-distal main orientation) to the resultant (antero-posterior) force. The resultant force thus seems to act all along the bone rather homogeneously, with only limited local tension, except along the anterior side. A similar general orientation of the trabeculae is also observed in humans (Raux et al., 1975; Toumi et al., 2006).

The dominant antero-posterior orientation in perissodactyls is stronger in the proximal than in the lower half of the bone, suggesting either stronger compressive stresses in the proximal half of the patella, or stronger tension in the lower half. And, indeed, equids and, to a lesser extent tapirs, show a second slight proximo-distal orientation of the trabeculae (observed on the CS) in the lower half, that would rather follow proximo-distal tension. In all specimens, trabeculae near the anterior cortex tend to align rather proximo-distally but along the anterior surface, probably reflecting the traction of the patellar ligament, and possibly also of the quadriceps tendon.

For all specimens, there is a slightly more intense thickening of the cortex and increase in the compactness of the spongiosa posteriorly in SS2 than in SS1. It is probably associated with a stronger compressive stress at the apex than in the medial articular facet, which is also in accordance with some cortical thickening on the apex in most specimens. 
Contrary to our hypothesis, there is no significant correlation of bone - including trabecular compactness with size and thus with body mass. Only an increase in the tightness of the spongiosa is observable, i.e. trabeculae appear more numerous and thinner, with reduced intertrabecular spaces, which is in accordance with multiple microanatomical studies (e.g. Dumont et al., 2013; Plasse et al., 2019).

\section{Trends among Perissodactyla}

The quantitative analyses highlight a strong variation within the perissodactyl families. There is also high intraspecific variation, notably observed among tapirs in our sample, since rhino specimens from the same species tend to group together in most cases and since only one equid species is represented by two specimens although these are two subspecies with strong differences in size and gracility. Intraspecific variation would need a larger sample to be analyzed in more detail. Information relative to captive versus wild origin, sex and even age (between subadult and adult specimens) are incomplete (Table 1) but no strong relationship of intraspecific variation with these three factors that might have been visible in such a limited sample is observed. This important intrafamily and intraspecific variation is consistent with previous studies highlighting a stronger variability of sesamoid bones as compared to other bones, in part because they are embedded in soft tissues that are also variable (Raymond \& Prothero, 2012; Clark \& Stechschulte, 1998; Samuels et al., 2007). Despite this variation, some clear differences are observed between the three perissodactyl families.

Equids have a clearly thinner cortex than ceratomorphs and this is notably characterized, beyond a generally lower thickness, by a much lower thickening in anterior view. This notable feature might be associated with a higher gracility and a relatively high position of the knee in equids (with proportionally much longer zeugopod and, especially, autopod bones) engendering different biomechanical constraints on the patella. Comparable analyses in other groups, such as early rhinocerotoids, notoungulates, artiodactyls and proboscideans would be required in order to functionally understand this adaptive trend.

In equids (also very slightly in some rhinos but not in tapirs) there is a circumferential orientation of the trabeculae between the apex and the medial border (observed in CS). This might be associated with the medial extension of the medial angle, with a medial displacement of the medial patellar ligament. Among perissodactyls, both rhinos and equids show a strongly asymmetrical femoral trochlea, with a much larger medial trochlear ridge (Hermanson \& MacFadden, 1996; Janis et al., 2012). This feature convergently evolved in these two lineages and in others, such as 
artiodactyls and notoungulates (Hermanson \& MacFadden, 1996; Shockey, 2001; Janis et al. 2012). It is supposed to increase the locking mechanism of the knee and thus to constitute a passive stay-apparatus (Hermanson \& MacFadden, 1996; Shockey, 2001; Janis et al. 2012). This would be of particular interest in animals with long periods of standing, like Equus caballus that stands for more than 20 hours a day (Boyd et al. 1988), but also in heavy taxa, so that this locking mechanism has been inferred to be also associated with body weight support (Hermanson \& MacFadden, 1996). Shockey (2001) insisted on the associated increase in the tension of the medial patellar ligament that would also restrict the medio-lateral movements of the tibia and thus increase limb stability during locomotion (Janis et al. 2012). As a consequence, knee asymmetry was tentatively associated with a galloping locomotor gait and high body mass. This would explain its evolution within perissodactyls, with all modern perissodactyls being able to gallop (Hildebrand, 1977; Leach \& Dagg, 1983; Alexander \& Pond, 1992; MacLaren \& Nauwelaerts, 2016). However, if the transverse gallop is most common in equids and rhinos, tapirs essentially resort to rotary gallop (Economou et al., 2021). This distinction in the type of gallop is common between small and large ungulates and might explain the joint association of locomotion and weight with knee asymmetry (larger galloping ungulates showing more asymmetric knees; Janis et al., 2012). Despite the development of the medial border, it is laterally and not medially that trabecular bone is denser in rhinos and equids (whereas it is more homogeneous in tapirs), suggesting stronger stress laterally (since bone compactness generally increases with stress intensity; Fyhrie \& Kimura, 1999; Keaveny et al. 2001; Perilli et al. 2008). This feature is in accordance with more forces being transmitted laterally because of the laterally deviated position of the knee. Trabecular tightness appears looser, i.e., less numerous trabeculae and relatively thicker trabeculae and intertrabecular spaces, in tapirs but compactness does not differ from that of rhinos and equids. Considering that tapirs do not show a development of the medial angle, we could have expected a "compensation" of the inner structure, with an increased compactness medially associated with higher stresses, but this is not the case, which suggests different repartition of stresses on their knees associated with a different patellofemoral joint.

\section{Conclusion}

The microanatomy of the entire patella in perissodactyls consists of a spongiosa surrounded by a compact cortex. As against our predictions, there is no increase in compactness with size. The muscle insertions are not associated with local thickening of the cortex; however, a strong 
thickening occurs at the insertion of the intermediate patellar ligament. The main orientation of the trabeculae, and therefore of the main stress, is anteroposterior, whereas anteriorly the trabeculae are more circumferentially oriented, following the insertion of the patellar ligament and, possibly, the quadriceps tendon. Variations occur within and between the three modern families. Ceratomorphs have a relatively thicker cortex than equids. The presence of a medial border in rhinos and equids is associated with increased trabecular density laterally, suggesting greater lateral stress. In contrast, the internal structure is more homogeneous in tapirs. These differences suggest that the diverse morphologies of the patellofemoral joints in the three families are associated with distinct stresses on their knees, raising the interest of further biomechanical investigations.

\section{Acknowledgments}

We warmly thank J. Lesur (MNHN, Paris, France), R. Portela-Miguez (Natural History Museum, London, UK), and L. Costeur (Naturhistorisches Museum Basel, Switzerland) for the loan of specimens. We are grateful to V. Fernandez (Imaging and Analysis Centre, NHM) and M. Bellato (UMS 2700, Paris, France) for performing scans and reconstructions, R. Lebrun (ISEM, plateforme MRI, Montpellier, France) for access and assistance to the MRI platform and the MRI platform member of the national infrastructure France-BioImaging supported by the French National Research Agency (ANR-10-INBS-04, «Investments for the future»), the labex CEMEB (ANR-10-LABX-0004) and NUMEV (ANR-10-LABX-0020). We also acknowledge C. Bader and A. Delapré (MNHN, Paris, France) for advises relative to the 3D cartographies, and C Etienne and C. Mallet (MNHN, Paris, France) for enriching discussions. We warmly thank two anonymous reviewers for their great comments that improved the manuscript, and Phil Cox for editorial work. AH acknowledges financial support from the ERC-2016-STG-715300.

The data that support the findings will be available in the 3Dthèque of the MNHN https://3dtheque.mnhn.fr/ and on MophoSource.

\section{References}


Abumandour, M.M.A,. Bassuoni, N.F., El-Gendy, S., Karkoura, A. \& El-Bakary, R. (2020). Cross-anatomical, radiographic and computed tomographic study of the stifle joint of donkeys (Equus africanus asinus). Anatomia, Histologia, Embryologia, 49, 402-416.

Aglietti, P. \& Menchetti, P.P.M. (1995) Biomechanics of the patellofemoral joint, in: The Patella. Springer, pp. 25-48.

Alexander, R. \& Pond, C. (1992) Locomotion and bone strength of the white rhinoceros, Ceratotherium simum. Journal of Zoology, 227, 63-69.

Alexander, R.M. \& Dimery, N.J. (1985) The significance of sesamoids and retro-articular processes for the mechanics of joints. Journal of Zoology, 205, 357-371. https://doi.org/10.1111/j.1469-7998.1985.tb05622.x

Allen, V., Kambic, R., Gatesy, S. \& Hutchinson, J. (2017) Gearing effects of the patella (knee extensor muscle sesamoid) of the helmeted guineafowl during terrestrial locomotion. Journal of Zoology, 303, 178-187.

Amson, E., Billet, G. \& de Muizon, C. (2018) Evolutionary adaptation to aquatic lifestyle in extinct sloths can lead to systemic alteration of bone structure. Proceedings of the Royal Society B: Biological Sciences, 285, 20180270.

Barone, R., (2000). Anatomie comparée des mammifères domestiques. Tome 2 : Arthologie et myologie. Paris: Vigot Frères.

Barone R. (2010). Anatomie comparée des mammifères domestiques. Tome 1 : Ostéologie. Paris: Vigot Frères.

Barr, W.A. (2018) Ecomorphology. Methods in paleoecology, 339-349.

Benjamin, M., Toumi, H., Ralphs, J., Bydder, G., Best, T. \& Milz, S. (2006). Where tendons and ligaments meet bone: attachment sites ('entheses') in relation to exercise and/or mechanical load. Journal of anatomy, 208, 471-490.

Bird, E.E., Kivell, T.L. \& Skinner, M.M. (2021). Cortical and trabecular bone structure of the hominoid capitate. Journal of Anatomy.

Blomberg, S.P., Garland, T. \& Ives, A.R. (2003) Testing for phylogenetic signal in comparative data: behavioral traits are more labile. Evolution, 57, 717-745.

Bongianni, M. (1988) Simon and Schuster's Guide to Horses and Ponies of the World. Simon and Schuster.

Boyd, L.E., Carbonaro, D.A. \& Houpt, K.A. (1988) The 24-hour time budget of Przewalski horses. Applied Animal Behaviour Science, 21, 5-17.

Budras, K.D., Sack, W.O. \& Rock, S. (2003). Anatomy of the horse: an illustrated text. Schlütersche. 
554 Buffrénil, V de., Canoville, A., D’Anastasio, R. \& Domning, D.P. (2010) Evolution of

555 Sirenian pachyosteosclerosis, a model-case for the study of bone structure in aquatic

556 tetrapods. Journal of Mammalian Evolution, 17, 101-120. https://doi.org/10.1007/s10914-

$557 \quad 010-9130-1$

558 Canoville, A., Buffrénil, V. \& Laurin, M. (2016) Microanatomical diversity of amniote ribs:

559 an exploratory quantitative study. Biological Journal of the Linnean Society, 118, 706-733.

560 Carter, D.R., Wong, M. \& Orr \& T.E. (1991) Musculoskeletal ontogeny, phylogeny, and

561 functional adaptation. Journal of Biomechanics, 24, 3-16.

562 Clark, J. \& Stechschulte, D.J. (1998) The interface between bone and tendon at an insertion

563 site: a study of the quadriceps tendon insertion. Journal of Anatomy, 192, 605-616.

564 https://doi.org/10.1046/j.1469-7580.1998.19240605.x

565 Currey, J.D. (2003) The many adaptations of bone. Journal of Biomechanics, 36, 1487-1495.

566 https://doi.org/10.1016/S0021-9290(03)00124-6

567 Dan, M., Parr, W., Broe, D., Cross, M. \& Walsh, W.R. (2018). Biomechanics of the knee

568 extensor mechanism and its relationship to patella tendinopathy: A review. Journal of

569 Orthopaedic Research, 36, 3105-3112.

570 David, C.C. \& Jacobs, D.J. (2014) Principal Component Analysis: A Method for Determining

571 the Essential Dynamics of Proteins, in: Protein Dynamics, Methods in Molecular Biology.

572 Humana Press, Totowa, NJ, pp. 193-226. https://doi.org/10.1007/978-1-62703-658-0_11

573 Díaz-Berenguer, E., Badiola, A., Moreno-Azanza, M. \& Canudo, J.I. (2018) First adequately-

574 known quadrupedal sirenian from Eurasia (Eocene, Bay of Biscay, Huesca, northeastern

575 Spain). Scientific Reports, 8, 1-13. https://doi.org/10.1038/s41598-018-23355-w

576 Doube, M., Kłosowski, M.M., Arganda-Carreras, I., Cordelières, F.P., Dougherty, R.P.,

577 Jackson, J.S., Schmid, B., Hutchinson, J.R. \& Shefelbine, S.J. (2010) BoneJ: Free and

578 extensible bone image analysis in ImageJ. Bone, 47, 1076-1079.

579 Dumont, M., Laurin, M., Jacques, F., Pelle, E., Dabin, W. \& de Buffrenil, V. (2013) Inner

580 architecture of vertebral centra in terrestrial and aquatic mammals: a two-dimensional

581 comparative study. Journal of Morphology, 274, 570-84. https://doi.org/10.1002/jmor.20122

582 Dunmore, C.J., Bardo, A., Skinner, M.M. \& Kivell, T.L. (2020) Trabecular variation in the

583 first metacarpal and manipulation in hominids. American Journal of Physical Anthropology,

584 171, 219-241. https://doi.org/10.1002/ajpa.23974

585 Dunn, R.H. (2018) Functional morphology of the postcranial skeleton, in: Methods in

586 Paleoecology. Springer, pp. 23-36. 
Economou, G., McGrath, M., Wajsberg, J. \& Granatosky, M.C. (2021) Perissodactyla Locomotion, in: Vonk, J., Shackelford, T. (Eds.), Encyclopedia of Animal Cognition and Behavior. Springer International Publishing, Cham, pp. 1-8. https://doi.org/10.1007/978-3319-47829-6_887-1

Ellis, M.I., Seedhom, B.B., Wright, V. \& Dowson, D. (1980) An evaluation of the ratio between the tensions along the quadriceps tendon and the patellar ligament. Engineering in Medicine, 9, 189-194. https://doi.org/10.1243/EMED_JOUR_1980_009_049_02

Etienne, C., Houssaye, A. \& Hutchinson, J.R. (2021). Limb myology and muscle architecture of the Indian rhinoceros Rhinoceros unicornis and the white rhinoceros Ceratotherium simum (Mammalia: Rhinocerotidae). PeerJ 9: e11314.

Eyal, S., Blitz, E., Shwartz, Y., Akiyama, H., Schweitzer, R. \& Zelzer, E. (2015). On the development of the patella. Development, 142, 1831-1839.

Eyal, S., Rubin, S., Krief, S., Levin, L. \& Zelzer, E. (2019). Common cellular origin and diverging developmental programs for different sesamoid bones. Development, 146, $\operatorname{dev} 167452$.

Ferry, B., Duclos, M., Burt, L., Therre, P., Le Gall, F., Jaffré, C. \& Courteix, D. (2011) Bone geometry and strength adaptations to physical constraints inherent in different sports: comparison between elite female soccer players and swimmers. Journal of bone and mineral metabolism, 29, 342-351.

Fujikawa, K., Seedhom, B.B. \& Wright, V. (1983). Biomechanics of the patello-femoral joint. Part I: A study of the contact and the congruity of the patello-femoral compartment and movement of the patella. Engineering in Medicine, 12, 3-11.

Fyhrie, D.P. \& Kimura, J.H. (1999). Cancellous bone biomechanics. Journal of Biomechanics, 32, 1139-1148.

Gould, S.J. (2002) The structure of evolutionary theory. Harvard University Press.

Hermanson, J.W. \& Macfadden, B.J. (1996) Evolutionary and functional morphology of the knee in fossil and extant horses (Equidae). Journal of Vertebrate Paleontology, 16, 349-357. Hildebrand, M. (1977) Analysis of asymmetrical gaits. Journal of Mammalogy, 58, 131-156. Houssaye, A. \& Tafforeau, P. (2012). What vertebral microanatomy reveals about the ecology of juvenile mosasaurs (Reptilia, Squamata). Journal of Vertebrate Paleontology, 32, 10421048.

Houssaye, A., Fernandez, V. \& Billet, G. (2016a) Hyperspecialization in some South American endemic ungulates revealed by long bone microstructure. Journal of Mammalian Evolution, 23, 221-235. 
Houssaye, A., Sander, P.M. \& Klein, N. (2016b) Adaptive patterns in aquatic amniote bone microanatomy-More complex than previously thought. Integrative and Comparative Biology, 56, 1349-1369.

Houssaye, A., Tafforeau, P. \& Herrel, A. (2014) Amniote vertebral microanatomy-what are the major trends? Biological Journal of the Linnean Society, 112, 735-746.

Houssaye, A., Waskow, K., Hayashi, S., Cornette, R., Lee, A.H. \& Hutchinson, J.R. (2016c) Biomechanical evolution of solid bones in large animals: a microanatomical investigation. Biological Journal of the Linnean Society, 117, 350-371.

Houssaye, A., Taverne, M. \& Cornette, R. (2018) 3D quantitative comparative analysis of long bone diaphysis variations in microanatomy and cross-sectional geometry. Journal of anatomy, 232, 836-849.

Huiskes, R., Ruimerman, R., Van Lenthe, G.H. \& Janssen, J.D. (2000) Effects of mechanical forces on maintenance and adaptation of form in trabecular bone. Nature, 405, 704-706.

Iwaniec, U.T. \& Turner, R.T. (2016) Influence of body weight on bone mass, architecture and turnover. Journal of Endocrinology, 230, R115-R130.

Janis, C.M., Shoshitaishvili, B., Kambic, R. \& Figueirido, B. (2012) On their knees: distal femur asymmetry in ungulates and its relationship to body size and locomotion. Journal of Vertebrate Paleontology, 32, 433-445.

Jang, I.G. \& Kim, I.Y. (2009). Computational simulation of trabecular adaptation progress in human proximal femur during growth. Jouranl of Biomechanics, 42, 573-580.

Jones, K.E., Benitez, L., Angielczyk, K.D. \& Pierce, S.E. (2018) Adaptation and constraint in the evolution of the mammalian backbone. BMC Evolutionary Biology, 18, 1-13.

https://doi.org/10.1186/s12862-018-1282-2

Keaveny, T.M., Morgan, E.F., Niebur, G.L. \& Yeh, O.C. (2001). Biomechanics of trabecular bone. Annual review of biomedical engineering, 3, 307-333.

Kivell, T.L. (2016) A review of trabecular bone functional adaptation: what have we learned from trabecular analyses in extant hominoids and what can we apply to fossils? Journal of Anatomy, 228, 569-594.

Kivell, T.L., Davenport, R., Hublin, J.J., Thackeray, J.F. \& Skinner, M.M. (2018). Trabecular architecture and joint loading of the proximal humerus in extant hominoids, Ateles, and Australopithecus africanus. American Journal of Physical Anthropology 167: 348-365. Kley, N., Kearney, M. \& Hall, B. (2007) Adaptations for digging and burrowing. Fins into limbs: evolution, development, and transformation, 284-309. 
654

655

656

657

658

659

660

661

662

663

664

665

666

667

668

669

670

671

672

673

674

675

676

677

678

679

680

681

682

683

684

685

686

Leach, D.H. \& Dagg, A.I. (1983) A review of research on equine locomotion and biomechanics. Equine Veterinary Journal, 15, 93-102. https://doi.org/10.1111/j.20423306.1983.tb01726.x

Lovejoy, C.O. (2007) The natural history of human gait and posture: Part 3. The knee. Gait and posture $25,325-341$.

MacLaren, J.A. \& Nauwelaerts, S. (2016) A three-dimensional morphometric analysis of upper forelimb morphology in the enigmatic tapir (Perissodactyla: Tapirus) hints at subtle variations in locomotor ecology. Journal of Morphology, 277, 1469-1485.

Montañez-Rivera, I., Nyakatura, J.A. \& Amson, E. (2018) Bone cortical compactness in 'tree sloths' reflects convergent evolution. Journal of Anatomy, 233, 580-591.

Montoya-Sanhueza, G. \& Chinsamy, A. (2018) Cortical bone adaptation and mineral mobilization in the subterranean mammal Bathyergus suillus (Rodentia: Bathyergidae): effects of age and sex. PeerJ, 6, e4944.

Mottershead, S. (1988) Sesamoid bones and cartilages: an enquiry into their function. Clinical Anatomy, 1, 59-62.

Perilli, E., Baleani, M., Öhman, C., Fognani, R., Baruffaldi, F. \& Viceconti, M. (2008).

Dependence of mechanical compressive strength on local variations in microarchitecture in cancellous bone of proximal human femur. Journal of Biomechanics, 41, 438-446.

Pina, M., DeMiguel, D., Puigvert, F., Marcé-Nogué, J. \& Moyà-Solà, S. (2020) Knee function through finite element analysis and the role of Miocene hominoids in our understanding of the origin of antipronograde behaviours: the Pierolapithecus catalaunicus patella as a case study. Palaeontology, 63, 459-475.

Plasse, M., Amson, E., Bardin, J., Grimal, Q. \& Germain, D. (2019) Trabecular architecture in the humeral metaphyses of non-avian reptiles (Crocodylia, Squamata and Testudines):

Lifestyle, allometry and phylogeny. Journal of Morphology, 280, 982-998. https://doi.org/10.1002/jmor.20996

Quemeneur, S., Buffrénil, V. \& Laurin, M. (2013) Microanatomy of the amniote femur and inference of lifestyle in limbed vertebrates. Biological Journal of the Linnean Society, 109, $644-655$.

Raux, P., Townsend, P.R., Miegel, R., Rose, R.M. \& Radin, E.L. (1975) Trabecular architecture of the human patella. Journal of Biomechanics, 8, 1-7.

Raymond, K.R. \& Prothero, D.R. (2010) Comparative variability of intermembranous and endochondral bones in Pleistocene mammals. Palaeontologia Electronica, 13, 4A. 
687

688

689

690

691

692

693

694

695

696

697

698

699

700

701

702

703

704

705

706

707

708

709

710

711

712

713

714

715

716

717

718

Reina, N., Cavaignac, E., Trousdale, W.H., Laffosse, J. \& Braga, J. (2017). Laterality and grip strength influence hand bone micro-architecture in modern humans, an HR p QCT study. Journal of Anatomy, 230, 796-804.

Saers, J.P., Ryan, T.M. \& Stock, J.T. (2020) Baby steps towards linking calcaneal trabecular bone ontogeny and the development of bipedal human gait. Journal of Anatomy, 236, 474492. https://doi.org/10.1016/j.jhevol.2016.05.012

Saers, J.P.P., Cazorla-Bak, Y., Shaw, C.N., Stock, J.T. \& Ryan, T.M. (2016) Trabecular bone structural variation throughout the human lower limb. Journal of Human Evolution, 97, 97108.

Samuels, M.E., Regnault, S. \& Hutchinson, J.R. (2017) Evolution of the patellar sesamoid bone in mammals. PeerJ, 5, e3103.

Sarin, V.K. \& Carter, D.R. (2000) Mechanobiology and joint conformity regulate endochondral ossification of sesamoids. Journal of Orthopaedic Research, 18, 706-712. Seilacher, A. (1970) Arbeitskonzept zur Konstruktions-Morphologie. Lethaia, 3, 393-396. Shockey, B.J. (2001) Specialized knee joints in some extinct, endemic, South American herbivores. Acta Palaeontologica Polonica, 46, 277-288.

Sievänen, H. (2010). Immobilization and bone structure in humans. Archives of biochemistry and biophysics, 503, 146-152.

Steiner, C.C. \& Ryder, O.A. (2011) Molecular phylogeny and evolution of the Perissodactyla. Zoological Journal of the Linnean Society, 163, 1289-1303.

Thomason, J.J. (1985) Estimation of locomotory forces and stresses in the limb bones of Recent and extinct equids. Paleobiology, 11, 209-220.

Toumi, H., Higashiyama, I., Suzuki, D., Kumai, T., Bydder, G., McGonagle, D., Emery, P., Fairclough, J. \& Benjamin, M. (2006) Regional variations in human patellar trabecular architecture and the structure of the proximal patellar tendon enthesis. Journal of Anatomy, 208, 47-57.

Valois, H. (1917) La valeur morphologique de la rotule chez les mammifères. Bulletins et Mémoires de la Société d'Anthropologie de Paris, 8, 1-34.

Vlachopoulos, D., Barker, A.R., Ubago-Guisado, E., Fatouros, I.G., Knapp, K.M., Williams, C.A. \& Gracia-Marco, L. (2017) Longitudinal adaptations of bone mass, geometry, and metabolism in adolescent male athletes: The PRO-BONE Study. Journal of Bone and Mineral Research, 32, 2269-2277. 
Volpato, V., Viola, T.B., Nakatsukasa, M., Bondioli, L. \& Macchiarelli, R. (2008) Textural characteristics of the iliac-femoral trabecular pattern in a bipedally trained Japanese macaque. Primates, 49, 16-25. https://doi.org/10.1007/s10329-007-0053-2 Wang, X.M., Liu, H.X., Niu, J.H., Duan, G.M. \& Wang, F. (2016). Relationship between the patellar ridge and the femoral trochlea in the patellar tracking. Orthopaedic Surgery, 8, 468474.

725 Warden, S.J., Fuchs, R.K., Castillo, A.B., Nelson, I.R. \& Turner, C.H. (2007). Exercise when 726 young provides lifelong benefits to bone structure and strength. Journal of Bone and Mineral 727 Research, 22, 251-259.

728 Wilson, D.E. \& Mittermeier, R.A. (2011) Handbook of the Mammals of the World. Vol. 2. 729 Lynx Edicions, Barcelona.

730 Wolff, J. (1986) Concept of the law of bone remodelling, in: The Law of Bone Remodelling. 731 Springer, pp. 1-1.

732 Yang, H., Embry, R.E. \& Main, R.P. (2017) Effects of loading duration and short rest 733 insertion on cancellous and cortical bone adaptation in the mouse tibia. PloS one, 12.

734 Zioupos, P., Currey, J.D., Casinos, A. \& Buffrénil, V.de (1997) Mechanical properties of the 735 rostrum of the whale Mesoplodon densirostris, a remarkably dense bony tissue. Journal of 736 Zoology, 241, 725-737. https://doi.org/10.1111/j.1469-7998.1997.tb05744.x 
Table 1. List of the material analyzed in this study. Mass from Bongianni (1988), Dinerstein (2011), Medici (2011), Rubenstein (2011), Wilson and Mittermeier (2011), and Yilmaz et al. (2012). Institutional abbreviations: NMB, Naturhistorisches Museum Basel, Switzerland; MNHN, Museum National d'Histoire Naturelle, Paris, France; NHMUK, Natural History Museum, London, UK. So: sample origin; C: captive; W: wild. S: sex; F: female; M: male. A: age; Ad; adult; SA: subadult. ?: unknown. Resol: resolution. ML: microtomography location; L: London, M: Montpellier, P: Paris.

\begin{tabular}{|c|c|c|c|c|c|c|c|c|}
\hline Family & Taxon & $\begin{array}{l}\text { Mass } \\
(\mathrm{kg})\end{array}$ & Collection number & So & $\mathrm{S}$ & $\mathrm{A}$ & $\begin{array}{l}\text { Resol } \\
(\mu \mathrm{m})\end{array}$ & ML \\
\hline \multirow{15}{*}{ 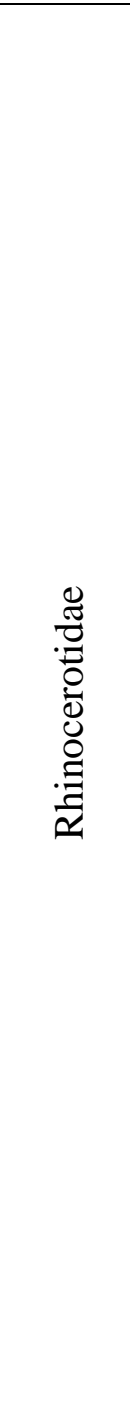 } & $\begin{array}{l}\text { Ceratotherium } \\
\text { simum }\end{array}$ & 2300 & $\begin{array}{l}\text { MNHN-ZM-MO- } \\
\text { 2005-297 }\end{array}$ & $\mathrm{C}$ & $\mathrm{M}$ & Ad & 61.8 & M \\
\hline & & & $\begin{array}{l}\text { NHMUK ZD } \\
2018.143\end{array}$ & $?$ & $?$ & Ad & 64.4 & $\mathrm{~L}$ \\
\hline & Diceros bicornis & $\begin{array}{l}800- \\
1300\end{array}$ & $\begin{array}{l}\text { MNHN-ZM-AC- } \\
\text { 1944-278 }\end{array}$ & $\mathrm{C}$ & $\mathrm{M}$ & Ad & 64.2 & M \\
\hline & & & $\begin{array}{l}\text { MNHN-ZM-AC- } \\
\text { 1936-644 }\end{array}$ & $?$ & $\mathrm{~F}$ & SA & 56.6 & M \\
\hline & & & NHM 1876.9.26.6 & $?$ & $?$ & $?$ & 74.8 & $\mathrm{~L}$ \\
\hline & $\begin{array}{l}\text { Dicerorhinus } \\
\text { sumatrensis }\end{array}$ & $\begin{array}{l}600- \\
950\end{array}$ & $\begin{array}{l}\text { NHMUK ZD } \\
1894.9 .24 .1\end{array}$ & $\mathrm{~W}$ & $?$ & Ad & 57.5 & $\mathrm{~L}$ \\
\hline & & & $\begin{array}{l}\text { NHMUK } \\
\text { ZE 1948.12.20.1 }\end{array}$ & $?$ & $?$ & Ad & 56.8 & $\mathrm{~L}$ \\
\hline & $\begin{array}{l}\text { Rhinoceros } \\
\text { sondaicus }\end{array}$ & $\begin{array}{l}1200- \\
1500\end{array}$ & $\begin{array}{l}\text { MNHN-ZM-AC- } \\
\text { A7970 }\end{array}$ & $?$ & $?$ & Ad & 66.8 & M \\
\hline & & & $\begin{array}{l}\text { NHMUK } \\
\text { ZD 1871.12.29.7 }\end{array}$ & $\mathrm{W}$ & $\mathrm{M}$ & Ad & 64.4 & M \\
\hline & & & $\begin{array}{l}\text { NHMUK } \\
\text { ZD 1921.5.15.1 }\end{array}$ & $\mathrm{W}$ & $\mathrm{F}$ & SA & 64.4 & $\mathrm{M}$ \\
\hline & & & $\begin{array}{l}\text { NHMUK ZD } \\
1861.3 .11 .1\end{array}$ & $\mathrm{~W}$ & $?$ & SA & 51.6 & M \\
\hline & $\begin{array}{l}\text { Rhinoceros } \\
\text { unicornis }\end{array}$ & 2000 & $\begin{array}{l}\text { MNHN ZM-AC- } \\
\text { 1967-101 }\end{array}$ & $\mathrm{C}$ & $\mathrm{F}$ & Ad & 68.8 & M \\
\hline & & & $\begin{array}{l}\text { NHMUK ZE } \\
1961.5 .10 .1\end{array}$ & $\mathrm{~W}$ & $\mathrm{M}$ & Ad & 82.2 & $\mathrm{~L}$ \\
\hline & & & $\begin{array}{l}\text { NHMUK } \\
\text { ZD 1972.822 }\end{array}$ & $?$ & $?$ & Ad & 74.8 & $\mathrm{~L}$ \\
\hline & & & $\begin{array}{l}\text { NHMUK } \\
\text { ZD 1884.1.22.1.2 }\end{array}$ & $\mathrm{W}$ & $\mathrm{F}$ & Ad & 74.8 & $\mathrm{~L}$ \\
\hline \multirow{2}{*}{ 寻 } & Tapirus indicus & $\begin{array}{l}280- \\
400\end{array}$ & $\begin{array}{l}\text { MNHN-ZM-AC- } \\
1931-528\end{array}$ & $\mathrm{C}$ & $\mathrm{M}$ & Ad & 44.9 & $\mathrm{M}$ \\
\hline & & & NMB 8125 & $\mathrm{C}$ & $\mathrm{F}$ & Ad & 52.2 & $\mathrm{P}$ \\
\hline
\end{tabular}




\begin{tabular}{|c|c|c|c|c|c|c|c|c|}
\hline & & & $\begin{array}{l}\text { MNHN ZM-AC- } \\
1935-460\end{array}$ & $\mathrm{C}$ & $\mathrm{M}$ & Ad & 52.2 & $\mathrm{P}$ \\
\hline & Tapirus pinchaque & $\begin{array}{l}150- \\
200\end{array}$ & $\begin{array}{l}\text { MNHN-ZM-AC- } \\
1982-34\end{array}$ & $\mathrm{C}$ & $\mathrm{M}$ & Ad & 44.9 & M \\
\hline & & & MNHN indet. & $?$ & $?$ & $?$ & 52.2 & $\mathrm{P}$ \\
\hline & Tapirus terrestris & $\begin{array}{l}180- \\
300\end{array}$ & $\begin{array}{l}\text { MNHN-ZM-MO- } \\
\text { 1990-20 }\end{array}$ & $\mathrm{C}$ & $\mathrm{M}$ & Ad & 44.3 & M \\
\hline & & & $\begin{array}{l}\text { MNHN-ZM-AC- } \\
1937-1\end{array}$ & $\mathrm{C}$ & $?$ & Ad & 52.2 & $\mathrm{P}$ \\
\hline \multirow{7}{*}{ 苞 } & Equus caballus & $\begin{array}{l}380- \\
600\end{array}$ & $\begin{array}{l}\text { MNHN-ZM-AC- } \\
1891-107\end{array}$ & $\mathrm{C}$ & $\mathrm{M}$ & Ad & 65.7 & $\mathrm{M}$ \\
\hline & & & $\begin{array}{l}\text { MNHN-ZM-AC- } \\
\text { A541 }\end{array}$ & $\mathrm{C}$ & $\mathrm{F}$ & $?$ & 55.2 & $\mathrm{M}$ \\
\hline & $\begin{array}{l}\text { Equus caballus } \\
\text { przewalskii }\end{array}$ & $\begin{array}{l}200- \\
300\end{array}$ & $\begin{array}{l}\text { MNHN-ZM-AC- } \\
1975-124\end{array}$ & $\mathrm{C}$ & $\mathrm{F}$ & $?$ & 56.5 & $\mathrm{M}$ \\
\hline & Equus asinus & $90-460$ & $\begin{array}{l}\text { MNHN-ZM-2005- } \\
717\end{array}$ & $?$ & $?$ & Ad & 65.8 & M \\
\hline & & & $\begin{array}{l}\text { MNHN-ZM-AC- } \\
1893-634\end{array}$ & $\mathrm{C}$ & $\mathrm{M}$ & $?$ & 50.9 & M \\
\hline & Equus hemionus & 200 & $\begin{array}{l}\text { MNHN-ZM-AC- } \\
1880-1103\end{array}$ & $\mathrm{C}$ & $\mathrm{M}$ & Ad & 44.3 & M \\
\hline & Equus zebra & $\begin{array}{l}240- \\
380\end{array}$ & $\begin{array}{l}\text { MNHN-ZM-AC- } \\
\text { 1948-54 }\end{array}$ & $\mathrm{C}$ & $\mathrm{F}$ & Ad & 56.9 & $\mathrm{M}$ \\
\hline
\end{tabular}

750

751

Table 2. Values obtained for the tests of a phylogenetic signal (data averaged by species) and allometric effect (all specimens separately) on the parameters analyzed. In bold when significant at $5 \%$.

755

756

\begin{tabular}{|c|c|c|c|c|c|c|c|c|}
\hline & $\mathrm{C}$ & \% Trab & $\mathrm{TC}$ & RMaxT & RMeanT & WBV & PC1 & PC2 \\
\hline$\overline{\mathrm{E}}$ & $\begin{array}{l}\mathrm{K}=0.59 \\
\mathrm{p}=0.36\end{array}$ & $\begin{array}{l}K=1.54 \\
p<0.01\end{array}$ & $\begin{array}{l}\mathrm{K}=0.60 \\
\mathrm{p}=0.28\end{array}$ & $\begin{array}{l}K=1.05 \\
p=0.01\end{array}$ & $\begin{array}{l}K=1.00 \\
p=0.02\end{array}$ & $\begin{array}{l}K=0.84 \\
p=0.04\end{array}$ & - & - \\
\hline is & $\begin{array}{l}\mathrm{r}=0.31 \\
\mathrm{p}=0.11\end{array}$ & $\begin{array}{l}r=0.16 \\
p=0.42\end{array}$ & $\begin{array}{l}\mathrm{r}=0.36 \\
\mathrm{p}=0.06\end{array}$ & $\begin{array}{l}r=0.04 \\
p=0.85\end{array}$ & $\begin{array}{l}\mathrm{r}=0.11 \\
\mathrm{p}=0.59\end{array}$ & - & $\begin{array}{l}\mathrm{r}=0.18 \\
\mathrm{p}=0.38\end{array}$ & $\begin{array}{l}\mathrm{r}=0.34 \\
\mathrm{p}=0.08\end{array}$ \\
\hline
\end{tabular}

757

758

759

760 
762

763

764

765

766

767

768

769

770

771

772

773

774

775

776

777

778

779

780

781

782

783

784

785

786

787

788

789

790

791

792

793

\section{Figure legends}

Figure 1. Phylogenetic tree including the taxa sampled; from Steiner and Ryder (2011).

Figure 2. Patellae of Ceratotherium simum NHMUK ZD 2018.143 (A,B), Equus caballus MNHN-ZM-AC-A541 (C,D) and Tapirus indicus MNHN-ZM-AC-1931-528 (E,F) illustrating the planes of the virtual sections.

Figure 3. Virtual coronal sections (CS) of the patellae of A, Ceratotherium simum $\mathrm{MNHN}$ ZM-MO-2005-297; B, Diceros bicornis MNHN-ZM-AC-1944-278; C, Dicerorhinus sumatrensis NHMUK ZD 1894.9.24.1; D, Rhinoceros sondaicus NHMUK ZD 1871.12.29.7; E, Rhinoceros unicornis NHMUK ZD 1972.822; F, Tapirus indicus MNHN ZM-AC-1935460; G, Tapirus pinchaque MNHN indet.; H, Tapirus terrestris MNHN-ZM-AC-1937-1; I, Equus caballus przewalskii MNHN-ZM-AC-1975-124; J, Equus asinus MNHN-ZM-2005717; K, Equus hemionus MNHN-ZM-AC-1880-1103; L, Equus zebra MNHN-ZM-AC-194854. Scale bars equal $1 \mathrm{~cm}$. Arrows point to large vascular canals.

Figure 4. Virtual sagittal sections (SS1) of A, Ceratotherium simum MNHN-ZM-MO-2005297; B, Dicerorhinus sumatrensis NHMUK ZD 1894.9.24.1; C, Tapirus indicus NMB 8125; D, Tapirus terrestris MNHN-ZM-MO-1990-20; E, Equus caballus MNHN-ZM-AC-1891107; F, Equus hemionus MNHN-ZM-AC-1880-1103. Scale bars equal $1 \mathrm{~cm}$.

Figure 5. Virtual sagittal sections (SS2) of A, Ceratotherium simum NHMUK ZD 2018.143; B, Rhinoceros unicornis NHMUK ZD 1972.822; C, Dicerorhinus sumatrensis NHMUK ZD 1894.9.24.1; D, Tapirus indicus MNHN ZM-AC-1935-460; E, Tapirus pinchaque MNHN indet.; F, Equus caballus MNHN-ZM-AC-A541. Scale bars equal $1 \mathrm{~cm}$.

Figure 6. Cartographies illustrating the relative differences in thicknesses among each bone individually (the maximal value differs between bones). Color varies from 0 (blue) to specimen's maximal thickness (red) (see Table S1). A-B, Dicerorhinus sumatrensis NHMUK ZE 1948.12.20.1; C-D, Rhinoceros sondaicus NHMUK ZD 1921.5.15.1; E, Rhinoceros unicornis NHMUK ZE 1961.5.10.1; F, Rhinoceros unicornis NHMUK ZD 1972.822; G-H, 
Tapirus indicus MNHN-ZM-AC-1931-528 ; I, Tapirus pinchaque MNHN-ZM-AC-1982-34;

795 J, Tapirus terrestris MNHN-ZM-MO-1990-20 ; K-L, Equus hemionus MNHN-ZM-AC-1880-

796 1103; M-N, Equus zebra MNHN-ZM-AC-1948-54; O-P, Equus caballus przewalskii MNHN-

797 ZM-AC-1975-124; in posterior (A, C, E, G, J, K, M, O) and anterior (B, D, F, H, I, L, N, P)

798 views. Scale bars equal $1 \mathrm{~cm}$.

799

800 Figure 7. Violin plots illustrating the variation of the various parameters among and between

801 the three families. R: Rhinocerotidae; T: Tapiridae; E: Equidae. C: bone compactness; \% Trab:

802 relative fraction of trabecular bone tissue; TC: trabecular compactness; RMaxT: relative

803 maximal cortical thickness; RMeanT: relative mean cortical thickness; WBV: whole bone

804 volume.

805

806 Figure 8. Distribution of the specimens in the morphospace along the two first axes of the

807 PCA with, on the top right, the contribution of the different parameters according to the

808 principal component (PC) axes PC1 and PC2. Color code for the species and complete names

809 of the parameters, as in Fig. 7.

810

811 Figure.9. Drawings illustrating the knee-joint of a horse in anterior view, notably the patellar

812 ligament insertions (A; modified from Barone, 2000), and muscle insertions on a horse patella

813 (B; modified from Barone, 2010). QF: Quadriceps femoris insertions. 